\title{
Immunoglobulin formation in B lymphoid cells
}

\author{
B. A. ASKONAS \\ From the National Institute for Medical Research, London
}

Immunoglobulin (Ig) molecules are formed by thymus-independent lymphoid cells, the B cell series, at various stages of maturation from resting lymphocytes to mature plasma cells; the latter are the cells which produce very large amounts of $\mathrm{Ig}$ ( $50 \%$ of total protein synthesis by the cell), and most of this Ig is secreted into the circulation. Since we are still uncertain whether thymus-derived lymphocytes ( $T$ cells) are able to produce any immunoglobulin at all, my remarks will be confined to Ig synthesis in the B cell series.

The small B lymphocytes express genes for Ig molecules but produce only small amounts of these proteins, most of which are associated with the outer cell surface. Although Ig represents only a small proportion of the cell's total protein production, the surface Ig molecules are of course essential for the recognition of antigen. On stimulation by the appropriate antigen these cells can be triggered to divide and differentiate into mature plasma cells. Antigen alone is not a sufficient stimulus in most cases; the triggering events are also under the control of other cells which interact with the B cells, ie, $\mathrm{T}$ cells and macrophages. The aspects of Ig synthesis which will be discussed are concerned with $(a)$ synthesis by fully mature differentiated cells; $(b)$ synthesis by the small lymphocytes; $(c)$ the induction of lymphocytes to divide and mature into plasma cells; and $(d)$ defects in Ig synthesis in myeloma cells.

Ig synthesis in B lymphoid cells follows all the rules for protein synthesis found in other eukaryotic cells and no special mechanisms for translation or gene transcription have been discovered. Originally it was thought that some special translational events might contribute to the extensive heterogeneity of Ig molecules in the serum which contains $10^{6}$ to $10^{7}$ different Ig molecules. However, no such special mechanisms have been discovered and it is now quite clear that the diversity of Ig molecules reflects the heterogeneity of the cell population which synthesizes Ig. Many different clones arise in individuals, each clone and its progeny forming one type of Ig molecule. Clonal selection thus forms the basis of a specific antibody response.

In lymphoid tissues there is the usual flow of information from DNA to messengerRNA(m-RNA) to protein. DNA contains the information for theo amino-acid sequence of the heavy $(\mathrm{H})$ and light $(\mathrm{L})$ 윽 chains of Ig, but the problem we need to elucidate iswhether each stem cell possesses a sufficient number of genes coding for the variable regions of $H$ and $L \vec{乛}$ chains to account for the heterogenous population of Ig molecules produced or whether there is only a small gene pool, antibody diversity being generated during the life of the animal by mutations. This ${ }^{\mathrm{T}}$ problem is still being widely debated (eg, Tonegawa, Steinberg, Dube, and Bernardini, 1974; Barstad, Farnsworth, Weigert, Cohn, and Hood, 1974). Ino any event, at some stage in its development the⿳䒑䶹 precursor cell has to choose to express one variable $\stackrel{\mathbb{Q}}{\stackrel{2}{ }}$ region and one constant region gene for each chain $\overrightarrow{\hat{0}}$ from its gene pool, be it small or large.

\section{Ig Synthesis by Plasma Cells}

A good deal is known concerning the formation and? assembly of Ig molecules in mature cells, mainly 3 . from in-vitro studies on cell suspensions of mouse or human plasma cells tumours and of spleen or 3 lymph nodes from immunized animals. Such studies have relied on the addition of 'pulses' of radioactive? amino acids followed by analyses of the Ig and its $\frac{?}{0}$ intermediates, both within the cells and in the medium (representing the secreted Ig), after specifics precipitation with the appropriate antiserum. Recent work in this field has been extensively reviewed (eg, Bevan, Parkhouse, Williamson, and Askonas, $\omega$ 1972; Askonas, 1974) and therefore the genera conclusions only will be summarized.

Ig molecules for export are formed by poly-\$ ribosomes aligned on membranes of the endoplasmic ${ }^{+}$ reticulum (ER). Heavy and light chains are produced independently on differently sized polyribosomes? which are of sufficient size for each chain to be? formed as a single polypeptide unit. Since two geneso code separately for the variable and constane regions of each chain the genes must be integrated 
at the gene level or they must be transcribed into a single m-RNA molecule by some mechanism. This has been confirmed recently by the isolation of $L$ and $\mathrm{H} \mathrm{m-RNA.} \mathrm{These} \mathrm{messenger} \mathrm{RNAs} \mathrm{consist} \mathrm{of}$ about 1200 and 1900 nucleotides respectively and are thus of sufficient size to code for the whole light chain and the whole heavy chain, and also contain some additional nucleotide sequences external to the code for variable and constant regions of $\mathrm{L}$ and $\mathrm{H}$ chains (eg, Stevens and Williamson, 1973; Tonegawa et al, 1974; Milstein, Brownlee, Cartwright, Jarvis, and Proudfoot, 1974b).

In the differentiated cell the chains are released rectorially into the vesicles of the endoplasmic reticulum (Bevan et al, 1972), where they are assembled within one to two minutes of synthesis into the basic four-chain Ig molecule $\left(\mathrm{L}_{2} \mathrm{H}_{2}\right)$ by disulphide bonding. A pool of light chains serves as an intermediate in assembly. This pool is small in normal plasma cells, turns over rapidly and is maintained within the cells. However, in plasma cell tumours the light chain pool varies in size, due to defects in the coordination of $L$ and $H$ chain synthesis and possibly in the alignment of polyribosomes on the ER membrane system. Ig is secreted via the smooth membranes while carbohydrate residues are added gradually during movement of the molecules through the rough and smooth membrane compartments of the cell.

The disulphide bonds in polymeric Ig are assembled more gradually. In mouse myeloma and normal spleen cells the intracellular precursor of IgM is the disulphide-linked, four-chain monomer $\left(\mu_{2} \mathrm{~L}_{2}\right)$ referred to as IgMs and approximately 7-8S in size. No significant amounts of polymer are present within the cell, so that polymerization into the pentameric 19S molecule occurs at the time of secretion and involves interchange of disulphide bonds, possibly mediated by an enzyme, and also the incorporation of one $J$ chain per 19S pentamer (Parkhouse and della Corte, 1973; Parkhouse, 1974). In some patients with IgM macroglobulinaemia the cells do accumulate 19S IgM (Buxbaum, Zolla, Scharff, and Franklin, 1971) but there is no evidence that this occurs in normal cells. IgA also polymerizes into dimers and trimers in the same way from $\alpha_{2} \mathrm{~L}_{2}$ monomers at the time of secretion. The fact that IgA is secreted mainly as a mixture of monomer, dimer and trimer is probably due to the formation of insufficient amounts of $J$ chain to permit polymerization of all the IgA subunits (Parkhouse, 1974). The finding that IgM is present as 7S subunits within the cell has a bearing on the size of the surface $\mathrm{Ig}$ receptors of IgM class on lymphoid cells (see below).

Heavy and light chain synthesis in plasma cells is normally regulated to provide a balanced synthesis of light and heavy chains to ensure that the major secretory products of the cell are fully assembled Ig molecules (Askonas, 1974). There is a small excess of light chain secretion observable in immune tissues which we found to be less than $5 \%$; the results obtained by different investigators have been somewhat variable. It is, however, clear that control of $\mathrm{H}$-chain synthesis is much more fragile than that of L-chains; cloning procedures of plasma cell tumour lines have shown that variant clones in which H-chain formation is partially or completely suppressed arise at a high frequency of $10^{-3}$ (Coffino, Lasteur, and Scharff, 1970). This suggests a regulatory variant rather than mutation of structural genes which appears to arise at a very low frequency in cultured myeloma cells (Milstein, Adetugbo, Cowan, and Secher, 1974a). Partial or complete suppression of $\mathrm{H}$-chain formation is also a frequent observation in vivo in myeloma patients. The table summarizes some of the defects in Ig production frequently observed in human and mouse myeloma.

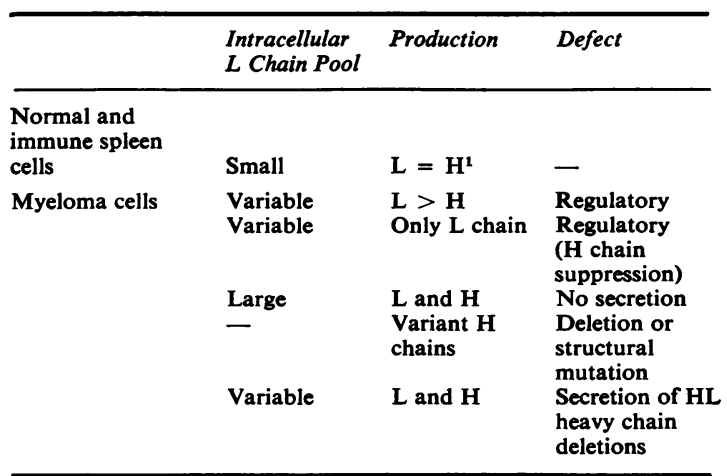

Table Defects in Ig production by myeloma cells

${ }^{1} \mathrm{~L}=$ light chain of $\mathbf{I g}, \mathbf{H}=$ heavy chain of $\mathbf{I g}$

Neoplastic plasma cells of mouse and man, both in vivo and in tissue cultures, frequently show disturbances in the synthesis and assembly of Ig molecules and their regulation.

Their susceptibility to these disturbances needs to be taken into consideration in the evaluation of such studies, and conclusions about normal control mechanisms in Ig synthesis therefore have to be based on studies of normal lymphoid cells as well.

In general each cell produces a single molecular species of immunoglobulin although there are some exceptions to this, as a proportion of circulating lymphocytes carry both IgD and IgM on their surface (Rowe, Hug, Forni, and Pernis, 1973). For example, one patient with Waldenström's macroglobulinaemia was found to have B lymphocytes in 
peripheral blood with both membrane-bound $\operatorname{IgM}$ and IgD, and both classes of surface receptors showed reactivity with IgG. After capping the receptors with aggregated IgG as antigen, both $\operatorname{IgD}$ and IgM reappeared on the lymphocyte surface suggesting that both of these molecules were being formed by the same cell (Pernis, Brouet, and Seligmann, 1974). Lymphoma cells in tissue culture often express more than one heavy or light chain, but these cells are malignant and it is not clear whether they suffer from faulty regulatory mechanisms or whether cells at an early stage of development have the ability to express more than one of the constant region genes simultaneously. There is, however, no doubt that at a later stage of normal differentiation only genes for a single species of Ig molecule are expressed, and that the immunoglobulin product of these cells remains the same throughout the life of a clone. This has become clear from our studies with antibody-forming cell clones in mice, which we selected and then propagated by sequential transfer of spleen cells in syngeneic mice (Askonas and Williamson, 1972). We found that the immunoglobulin product of these clones is remarkably stable. We have passaged such clones into as many as $\mathbf{5 0 0}$ mice and through up to eight transfers with an estimated $60-80$ successive cell divisions. Unfortunately we cannot passage these clones for even longer periods because these normal cells lose their proliferative capacity after about 60 to 80 cell divisions, unlike the myeloma cells which divide indefinitely (Williamson and Askonas, 1972). The Ig products of mouse plasmacytomas also remain unchanged when passaged over many years in syngeneic mice. In a myeloma patient the structure of the $\mathrm{L}$ or $\mathrm{H}$ chains of the myeloma protein produced also remains constant during the life of the patient, which may be several years. Although variants of mouse myeloma cells in cloned tissue culture cells have been detected (Morrison, Baumal, Birsthein, Knehl, Preud'homme, Frank, Jasek, and Scharff, 1974; Milstein et al 1974), structural variants of the Ig (deletions of part of the heavy chain gene or amino acid replacements) arise at very low frequency $\left(10^{-6}\right.$ cell generation) unless mutagens are used.

\section{Ig Production in Small B Lymphocytes}

Small lymphocytes form very small amounts of Ig, most of which is associated with the plasma membrane. The fact that Ig represents less than $1 \%$ of total cellular protein synthesis has been a handicap in the study of Ig formation by these cells as compared with plasma cells. However, recent techniques, including that of separation of the small lymphocytes

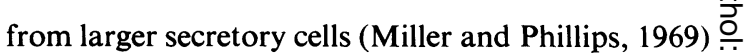
have assisted these studies. By iodination of plasma $\vec{F}$ membrane proteins, surface IgM molecules on $\stackrel{0}{+}$ B cells have been identified as the $\mu_{2} \mathrm{~L}_{2} 7 \mathrm{~S}$ mono- $\frac{\mathrm{C}}{\mathrm{O}}$ meric subunits, IgMs (Vitetta and Uhr, 1973; 음 Marchalonis and Cone, 1973), whereas mature cells $\frac{\sigma}{\sigma}$ secrete the IgM in its 19S pentamer form (Parkhouse, $\stackrel{\mathbb{D}}{\Omega}$ 1974). Estimates of turnover time of the IgMs $\%$ surface receptors are variable. Following iodination, $\overrightarrow{0}$ fairly rapid shedding of IgMs from B cells has been observed with a half life of several hours $\vec{\omega}$ (Marchalonis and Cone, 1973; Vitetta and Uhr, 1973); on the other hand, after labelling such? receptors biosynthetically with radioactive amino is acids, the half life is 20-48 hours (Melchers and Andersson, 1973; Andersson, Lafleur, and Melchers, $\vec{\infty}$ 1974). Similarly, a very slow release of surface 0 IgMs, $10 \%$ in eight hours, was reported following iodination of Daudi lymphoma cells in tissue $\vec{c}$ culture (Grundke-Iqbal and Uhr, 1974). These differences might be attributed to subpopulations of B lymphocytes with various rates of Ig receptor turnover or possibly to the deleterious effect of $\vec{\varphi}$ iodination on cell membrane structure leading toù cell death; hence, at present, work with biosynthetically labelled receptors probably gives the more reliable estimates.

According to Andersson, Lafleur, and Melchers, (1974) about $90 \%$ of the Ig in small lymphocytes is $\mathbb{Q}$ associated with the surface membrane. These cells $\underset{\vec{P}}{\overrightarrow{2}}$ do not secrete Ig, but slow shedding of the receptor molecules may occur thus accounting for the very slow turnover of these molecules (half life of 24 to 48 hours). This contrasts with the pattern of Ig synthesis in the mature secreting cell, which forms? about 100 times more immunoglobulin than the immature B lymphocyte. The density of Ig receptors: on the surface is low and most of the Ig formed is 0 secreted from the cell. Up to $50 \%$ of the cell's total protein synthesis is represented by Ig and there is a음 very rapid secretion of the intracellular Ig with a half life of about two hours. Ig secretion by many을. myeloma cells is much less efficient than secretion by the normal plasma cell; intracellular Ig tends to or turn over more slowly in myeloma cells with a half life of about four to six hours.

Conversion of Small Lymphocytes into Ig-secretingo Cells

It is not fully understood how a small lymphocyte matures into a plasma cell with high levels of antibody secretion. In a preliminary attempt to analyse this problem we have recently tried to relate the kinetics of DNA synthesis, of the transcription of Igo genes and of Ig synthesis, using a model system in 
which mouse spleen cells are triggered with lipopolysaccharide (LPS) from $E$ coli to divide and mature into IgM-secreting cells (Stevens, Askonas, and Welstead, 1975). In this system, short-term culture for four days does not induce IgG production but a major proportion of the $B$ lymphocytes is stimulated to divide and mature so that by the second day $40-50 \%$ of the cells have been activated into blast cells (Greaves and Janossy, 1972; Andersson, Sjöberg, and Möller, 1972). It would, of course, be preferable to carry out this type of study on B memory cells stimulated with antigen but, despite the multiclonal response to a single antigen, only a very small proportion of the cells (about 0.05 to $0.2 \%$ ) is stimulated by a given antigen so that too few cells take part in the reaction for satisfactory biochemical analysis. After LPS administration $\mathbf{H}$ chain m-RNA could be isolated in multiple samples using the technique of Stevens and Williamson (1973) who found that m-RNA for $\mathrm{H}$ chain (but not for $\mathrm{L}$ chain) interacts with $\mathrm{Ig}$ molecules. This interaction is neither species-specific nor Ig classspecific.

Mouse spleen cells in tissue culture stimulated with LPS show a 10- to 30-fold stimulation of DNA synthesis on the first or second day, as measured by the incorporation of ${ }^{3} \mathrm{H}$-thymidine, but peak levels of IgM synthesis and secretion occur on days 3 and 4, lagging at least 24 hours behind the peak of DNA synthesis. The transcription of m-RNA for H-chain parallels the DNA synthesis pattern, and is reduced by days 3 and 4 when Ig production is at its peak (Stevens et al, 1975). The results suggested a translation block on the freshly formed $H$ chain m-RNA until maturation of the cell had occurred. There was no apparent block on the transport of $\mathbf{H ~ m - R N A}$ from the nucleus during early stages of activation. Examination by electron microscopy (Shohat, Janossy, and Dourmashkin, 1973) confirms this pattern; 16-28 hours after the addition of LPS many B cells have become lymphoblasts with cytoplasmic polyribosomes, but development of the endoplasmic reticulum commences only after 28 hours and plasmablasts appear on day 3. Translation of the Ig message thus appears to be blocked until the cells are forming the endoplasmic reticulum to which polyribosomes can attach so that synthesis for export from the cell can commence.

\section{Summary}

A considerable amount is known about Ig biosynthesis by mature plasma cells, which form large amounts of Ig for secretion from the cell. A brief summary is given of the formation of light (L) and heavy $(\mathrm{H})$ chains by polyribosomes aligned on the endoplasmic reticulum and the rapid assembly of the chains into $7 \mathrm{~S}$ molecules $\left(\mathrm{H}_{2} \mathrm{~L}_{2}\right)$ by disulphide bonding. There is a time-ordered secretion from the cell of $7 \mathrm{~S} \mathrm{Ig}$ molecules; the polymeric forms of $\mathrm{Ig}$, ie, $\operatorname{IgM}$ and $\operatorname{IgA}$, are formed from monomers by disulphide bond interchange and $\mathbf{J}$ chain incorporation at the time of secretion.

Myeloma cells from mouse and man have proved very useful in this type of study but such malignant cells show many defects in regulatory mechanisms; therefore, no conclusions can be drawn about normal control mechanisms without analysis of lymphoid tissues from normal or immunized animals.

The pattern of Ig synthesis by the mature cell contrasts with that by small B lymphocytes which form $1 / 50$ to $1 / 100$ the amount of Ig produced by mature cells. Most of the small lymphocyte Ig is associated with the cell surface, and in IgMproducing cells the surface receptors are 7S monomer subunits of IgM. Such receptors turn over slowly (24-48 hours); they may be gradually shed from the cell surface but the small lymphocyte does not actively secrete Ig.

Antigen-and cell-cell interactions stimulate small B lymphocytes to divide and mature into Ig-secreting cells. Little is known about the associated intracellular events, but preliminary data on lipopolysaccaride-stimulated mouse spleen cells indicate that transcription of m-RNA for $\mathrm{H}$-chain mirrors the kinetics of DNA synthesis. A translational block then occurs during cell maturation and there is a lag of at least 24 hours before Ig production rises sharply and reaches peak levels.

\section{References}

Andersson, J., Lafleur, L., and Melchers, F. (1974). IgM in bonemarrow derived lymphocytes. Europ. J. Immunol., 4. 170.

Andersson, J., Sjöberg, O., and Möller, J. (1972). Mitogens as protes for immunocyte activation and cellular cooperation. Transplant. Rev., 11, 131 .

Askonas, B. A. (1974). Immunoglobulin biosynthesis and its control. Ann. Immunol. (Inst. Pasteur), 125c, 253.

Askonas, B. A., and Williamson, A. R. (1972). Factors affecting the propagation of a B-cell clone forming antibody to the 2, 4dinitrophenyl group. Europ. J. Immunol., 2, 487.

Barstad, P., Farnsworth, V., Weigert, M., Cohn, M., and Hood, L. (1974). Mouse immunoglobulin heavy chains are coded by multiple germ line variable region genes. Proc. nat. Acad. Sci. (Wash.), 71, 4096.

Bevan, M. J., Parkhouse, R. M. E., Williamson, A. R., and Askonas, B. A. (1972). Biosynthesis of immunoglobulins. Progr. Biophys. molec. Biol., 25, 133.

Buxbaum, J., Zolla, S., Scharff, M. D., and Franklin, E. C. (1971). Synthesis and assembly of immunoglobulins by malignant human plasmacytes and lymphocytes. II. Heterogeneity of assembly in cells producing IgM proteins. J. exp. Med., 133, 1118.

Coffino, P., Laskov, R., and Scharff, M. D. (1970). Immunoglobulin production: method for quantitatively detecting variant myeloma cells. Science, 167, 186

Greaves, M., and Janossy, G. (1972). Elicitation of selective T and B lymphocyte responses by cell surface binding ligands. Transplant. Rev., 11, 87. 
Grundke-Iqbal, I., and Uhr, J. W. (1974). Cell surface immunoglobulin. VI. Dynamics on a human lymphoma line. Europ. $J$. Immunol., 4, 159.

Marchalonis, J. J., and Cone, R. E. (1973). Biochemical and biological characteristics of lymphocyte surface immunoglobulin. Transplant. Rev., 14, 3.

Melchers, F., and Andersson, J. (1973). Synthesis, surface deposition and secretion of IgM in bone marrow-derived lymphocytes before and after mitogeneic stimulation. Transplant. Rev., 14, 76.

Miller, R. G., and Phillips, R. A. (1969). Separation of cells by velocity sedimentation. J. Cell Physiol., 73, 191.

Milstein, C., Adetugbo, K., Cowan, N. J., and Secher, D. S. (1974a), Clonal variants of myeloma cells. In Progress in Immunology II, Vol. 1, 157, edited by L. Brent and J. Holborrow, North Holland, Amsterdam.

Milstein, C., Brownlee, G. G., Cartwright, E. M., Jarvis, J. M., and Proudfoot, N. J. (1974b). Sequence analysis of Ig light chain messenger RNA. Nature (Lond.), 252, 354.

Morrison, S. L., Baumal, R., Birsthein, K., Knehl, M., Preud' homme, J. L., Frank, L., Jasek, T., and Scharff, M. D. (1974). In Cellular Selection and Regulation in the Immune Response, edited by G. M. Edelman, p. 233. Raven Press, New York.

Parkhouse, R. M. E. (1974). Biosynthesis of polymeric immunoglobulin. In Progress in Immunology II, Vol. 2, p. 119.
Parkhouse, R. M. E., and della Corte, E. (1973). Biosynthesis of을 immunoglobulin A and M. Biochem., 136, 597 and 607.

Pernis, B., Brouet, J. C., and Seligmann, M. (1974). IgD and IgM on the membrane of lymphoid cells in macroglobulinemia. Europ? J. Immunol., 4, 776.

Rowe, D. S., Hug, K., Forni, L., and Pernis, B. (1973). Immunoglobulin $\mathrm{D}$ as a lymphocyte receptor. J. exp. Med., 138, 965

Shohat, M., Janossy, G., and Dourmashkin, R. R. (1973). Develop- $-\frac{\mathscr{T}}{-}$ ment of rough endoplasmic reticulum in mouse splenio lymphocytes stimulated by mitogens. Europ. J. Immunol., 3 Q 680.

Stevens, R. H., Askonas, B. A., and Welstead, J. L. (1975). Immunoglobulin heavy chain m-RNA in mitogen stimulated B-cells $\overrightarrow{0}$ Europ. J. Immunol., 5, 47.

Tonegawa, S., Steinberg, C., Dube, S., and Bernardin, A. (1974) Evidence for somatic generation of antibody diversity. Proco nat. Acad. Sci. (Wash.), 71, 4027'

Vitetta, E. S., and Uhr, J. W. (1973). Synthesis, transport, dynamico? and fate of cell surface Ig and alloantigens in murine lymphois cytes. Transplant. Rev., 14, 50.

Stevens, R. H., and Williamson, A. R. (1973). Isolation of messenge'́ RNA coding for mouse heavy-chain immunoglobulin. Proc - nat. Acad. Sci. (Wash.), 70, 1127.

Williamson, A. R., and Askonas, B. A. (1972). Senescence of an antio body-forming cell clone. Nature (Lond.), 238, 337 . 